\title{
GENERALIZED COASE THEOREM
}

\author{
Jiří Hlaváček, Michal Hlaváček*
}

\begin{abstract}
:
In this article two original microeconomic models of an externality market are described: (1) model of optimal financial compensation of a damage caused by a negative externality in the economy with agents maximizing probability of their survival (generalized Coase Theorem) and (2) generalized model of optimal financial favour for agents provided a positive externality. Results of the models are compared with the outcomes of the standard microeconomics of subjects maximizing their own profit.
\end{abstract}

Keywords: negative externalities, marketable permits for exhalations, generalized Coase Theorem, maximizing of the probability of economic survival, positive externalities

JEL Classification: D62, D64

\section{Introduction}

In the presented article we apply our own methodology of generalized microeconomic theory for modelling the externalities (both negative and positive). We will illustrate how the generalization of the criteria leads to the change of the conclusions of the standard model.

The most important achievement of the standard microeconomics in the area of externalities is the Coase Theorem. This theorem shows that (given assumption of the zero transaction costs) the bargaining among influenced participants considering the private compensation for inflicted detriment leads for negative externalities to the socially efficient solution. Similarly the private bargaining leads to the socially efficient solution in case of subsidy for positive externality. Notable result of the Coase Theorem is also that the efficient solution for the problem of the externalities is achieved irrespective of the legal definition of the liability for damages.

One of the most interesting results arrived at Coase Theorem is the independency of the volume of investments for reduction of undesired effects of negative externalities (e.g. ecological investments) on the assignment of property rights when costless trades are possible. This result was many times tested and discussed.

The results of experimental tests published in the study Kahneman, D., Knetsch, J. L., Thaler, R. H. (1990) show, that volume of transactions predicted by Coase Theorem is always significantly more than really observed volume and that people place a higher

* Jiří Hlaváček, Institute of Economic Studies, Faculty of Social Sciences, Charles University, Prague (jihlava@fsv.cuni.cz); Michal Hlaváček, Institute of Economic Studies, Faculty of Social Sciences, Charles University, Prague and Czech National Bank (michal.hlavacek@cnb.cz) 
value on a good that they own than on an identical good that they do not own (the so called endowment effect). The loss aversion and the endowment effect lead to an impeachment of the result of Coase considering the independency of the assignment of property rights. Other experimental tests of the endowment effect for results of the Coase Theorem are published in Hoffman - Spitzer (1982) or Shogren (1982).

Number of authors questions lifelikeness of the Coase Theorem, especially assumption of zero transaction costs. Crucial importance of this assumption is highlighted by Coase himself: In his 1991 Nobel Prize acceptance speech (Persson, 1997) he made it clear that transaction costs are everywhere and thus property rights always make a difference. This could be understood as an appeal to the generalization of his theorem that was followed by a number of economists.

For example Martens (1996) argues that assuming exogenously fixed production technology and consumer preferences, as well as the availability of perfectly symmetric information at zero cost contradicts the real economy. His generalized version of the Coase Theorem is derived from the approach of bounded rationality and provides a more realistic basis than the neo-classical paradigm to explain a wider range of individual (economic) choice behaviour.

Bernholz (1999) analyzes Coase Theorem in cooperative game framework with respect to the final distribution of alienable property rights. Cooper (1995) put Coase Theorem into international economic relations context. Consideration of the attitude of the involved subjects towards risk (risk sharing, polluter's or victim's aversion or neutrality to risk) is presented in Zivin and Small (2003). Other questions of "Coasean Economics" are discussed by Medema and Samuels (1996).

Generalisation of the Coase Theorem is also model presented in this paper. On the contrary to the majority of other generalisations we do not abandon assumption of zero transaction costs. Our generalisation is based on criterion function of the involved subjects: we consider maximisation of the survival probability instead of income maximisation.

In the second part of this article we will shortly describe the basis of the generalized microeconomics concept. Third part includes formulation of the standard Coase Theorem for negative externalities and comparison of the market solution of the negative externality problem with Pigou tax. Fourth part models problem of externalities within environment of the subjects maximizing their probability of own survival. In the fifth part we shortly describe solution of the positive externalities problem in the standard microeconomics and in the sixth part we solve this problem again within the generalized microeconomic framework. The last part compares conclusions of the standard and generalized microeconomics for the problem of externalities.

\section{Generalized Microeconomic Criterion}

Theoretical conception of the generalized microeconomics (see Hlaváček J. and Hlaváček M., 2011) proceeds from the presumption that the economic criterion arises as a result of the Darwinist survival of the fittest; each successful (thus surviving in the long term) economic subject strives, at least intuitively, to avoid situations with high risk of its downfall. Thus we chose minimization of the subjectively felt probability of the downfall as a general criterion for the decision making of the economic subject. It 
could be assumed that such criterion establishes itself in liberalized market environment via natural selection: those subjects that do not behave by this way cease to exist.

We will consider that the subjective probability of downfall will be in direct proportion with the relative reserve to the zone of downfall (thus subsistence level). The asymmetric Pareto distribution of the first order is equivalent to this assumption.

If the only threat for the subject is its low income the agent decides for standard income maximization. However, in the case of higher number of mutually independent threats the subject chooses a compromise solution maximizing probability of its survival with respect to all threats at one time.

Generalized microeconomic model has allowed us to grasp a number of areas where the profit criterion either does not give full picture of the subjects' motivation or even does not make any sense. It concerns for example re-distribution (including donor activities of the state and of non-state subjects), non-profit sector, particularly university education, centrally planned economy or altruism. In addition, the generalized microeconomics has enabled a non-traditional and in some respects a deeper insight into other areas of microeconomics: risk modelling, the insurance market and the relationship "principal-agent" (moral hazard and unfavourable selection). Nevertheless, the concerned areas could not be deemed as insignificant. For example, redistribution (including donor activities) and non-profit sector of a market economy cover for more than half of financial operations in a modern economy.

We did not want to abandon the homo oeconomicus paradigm and to replace it with the criterion functions of the bodies, which is inconsistent with profit maximization. Because of many reasons we go another way: we try to extend the "scope" of microeconomics so that activities of non-profit entities are rendered in such a way that standard profit or benefit maximization be a special case. Therefore we did not abandon the homo oeconomicus paradigm but we generalise it so that this generalization does not deny standard microeconomics but complements it.

Maximization of survival probability is for us the generalising criterion. It need not be the criterion that is considered explicitly at everyday decision making of individual subjects. But if a subject does not take this criterion into account, it will economically cease to exist during time.

We assume, that the subject's survival probability is directly proportional to the share of his reserve (compared to subsistence level $b$ ) on his income $d$. This assumption is equivalent with the Pareto probability distribution of the first degree for probability of the survival. This distribution has asymmetric distribution function:

$$
\begin{array}{llll}
F(d)=0 & \text { for } & d \leq b \\
F(d)=\frac{d-b}{d} & \text { for } & d>b
\end{array}
$$

and which has density function of:

$$
\begin{array}{lll}
f(d)=0 & \text { for } & d<b \\
f(d)=\frac{b}{d^{2}} & \text { for } & d \geq b .
\end{array}
$$


Provided there are various threats of the subject, our modelling approach will enable us to find a compromise solution of a multicriterion problem that does not require vectorial optimization at the same time. There is the only maximized criterion: maximization of survival probability, i.e. maximization of probability of simultaneous avoidance of all risks threatening economic survival of the subject.

\section{Coase Theorem for Negative Externalities}

Negative externalities are activities comprising external costs impinging on the subjects that do not participate on these activities. They cause disruption of the competitive ideal: the relevant product seems to be cheaper then it is in reality from the point of view of the whole society. Produced amount of the good (depicted as $Y$ in the Figure 1 below) is in private optimum $\mathrm{E}_{\mathrm{p}}$ higher than it would be socially optimal (point $\mathrm{E}_{\mathrm{S}}$ ). Social costs of this inefficiency depicts the shaded area in Figure 1, where $\mathrm{MC}_{\mathrm{S}}$ and $\mathrm{MC}_{\mathrm{P}}$ depict the social and private marginal costs, $D$ depicts demand for the goods (social marginal utility).

Figure 1

Social Costs of Inefficiency due to Negative Externality

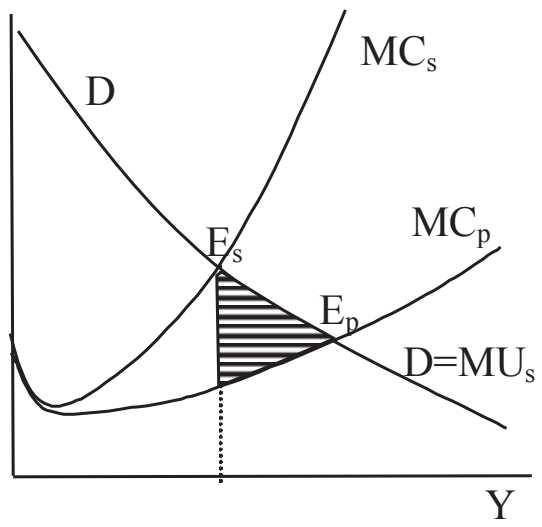

Inefficiency caused by the negative externality could be solved either by state intervention (especially by taxation of the relevant goods; see Pigou approach described thereinafter) or by state regulation that allows negotiation for compensation for harm. Two alternative legal regulations could be considered. In the first legal regulation the harmed has the right to forbid contaminator's production. He will not use this right only if he receives sufficient compensation. Under second legal regulation the harmed does not have any right to stop activity leading to contamination; however he could pay the contaminator compensation in exchange of his decrease of production (and contamination). 
Standard Coase Theorem could be formulated as following (Coase, 1960):

"Let us suppose, that

- property rights are well defined,

- people act rationally,

- transaction costs are zero.

Then bargaining among participants can achieve an efficient allocation of resources whatever the initial assignment of property rights.

A negotiation for compensation between subjects damaging and subjects damaged by negative externalities brings (under the assumption of negligible cost of negotiation) an efficient result, both under first and second legal regulation. Starting allocation of the legal entitlement does not have any long term influence on the efficiency unless the transaction costs are zero."

Classic example used in mentioned seminal Coase's paper explores situation of a doctor, whose work was harmed by noise made by a candy producer in the neighbour building. Traditional economic opinion was restrictive: noise harms doctor and therefore the candy producer is obliged to remove the source of noise. Coase noticed seemingly self-evident fact: removing the source of noise will indeed help the doctor, but will harm the candy producer. One way or the other, someone will always sustain harm. From the global point of view it is apparent, that it will be better if the alternative meaning smaller harm will be implemented. Coase supplements: if we enable negotiation between the damaged and the "guilty party", it is advantageous for both subjects to implement the alternative which embodies smaller damage.

Thus: If assumptions of the theorem are fulfilled, negotiation between subjects will logically lead to agreements advantageous for all involved parties and, at the same time, also to optimal allocation of resources on ecological investments. Producers will in their own interest achieve that what the State (because of an information scarcity) attempts vainly: negative externality reaches such level, which is optimal from the global viewpoint, e.g. from the viewpoint of possible joint owner of both firms.

Let us model problem of two producers (the contaminator and the harmed), whereas we assume zero (negligible) cost connected with their negotiation about possible reimbursement.

Let us mark:

$x \quad$ volume of contamination,

$\Pi(x)$ profit of contaminator from his activity which causes contamination at volume $x$,

$L(x) \quad$ financial loss of the subject damaged by contamination $\mathrm{x}$.

Optimum (efficient level of contamination) $x^{*}$ is solution of the equation

$$
\Pi^{\prime}(x)=L^{\prime}(x) \text {. }
$$

If $\Pi(x)$ is a concave function (thus its first derivative is decreasing in $x$ ) and $L(x)$ is a convex function (thus its first derivative is increasing in $x$ ), this is the necessary and sufficient condition for achieving efficient allocation. 
Figure 2

Efficient Level of Negative Externality

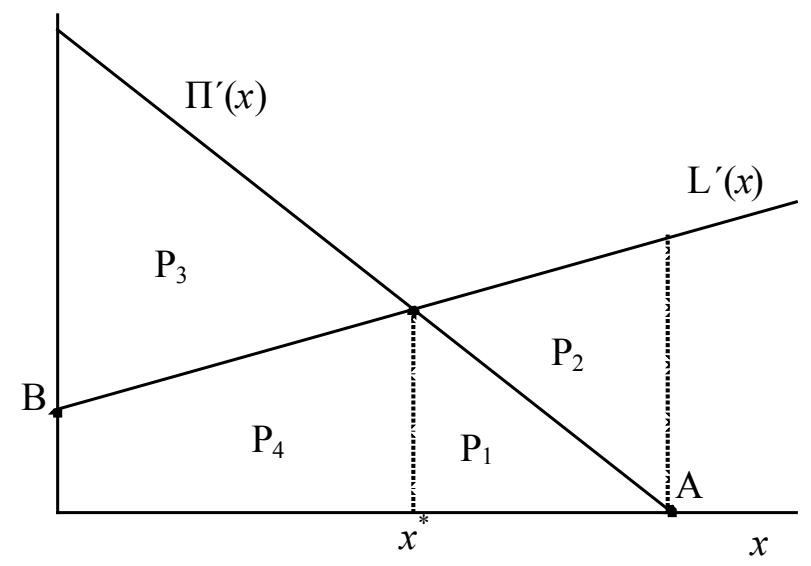

Source: Gravelle, Rees (1992) p. 518.

Figure 2 illustrates decreasing marginal contaminator's profit $\Pi^{\prime}(x)$ and increasing marginal damage of the harmed $L^{\prime}(x)$. Let us compare above mentioned two possible legal regulations:

\section{a) Legal regulation that allows the contaminator to harm the damaged as he likes.}

If the subjects do not make a deal about compensation, then the result is the situation illustrated by point $\mathrm{A}$, when the contaminator ignores the harm of the damaged. Under efficient level of contamination $x^{*}$ (optimal satisfaction) the contaminator loses (compared to situation A) a profit corresponding to area $\mathrm{P}_{1}$, loss of the damaged decreases by equivalent of area $\mathrm{P}_{1}+\mathrm{P}_{2}$. If subjects make a deal and the damaged pays the contaminator compensation in an amount

$$
\mathrm{P}_{1}+a . \mathrm{P}_{2} \text {, where } 0<a<1,
$$

as compensation for that he restricted production and thereby pollution. They both will - under efficient level of pollution $x^{*}$ - gain compared to situation A, because they will obtain:

- the contaminator amount $\quad \mathrm{P}_{1}+a \cdot \mathrm{P}_{2}-\mathrm{P}_{1}=a \cdot \mathrm{P}_{2}$

- the damaged amount $\quad \mathrm{P}_{1}+\mathrm{P}_{2}-\left(\mathrm{P}_{1}+a \cdot \mathrm{P}_{2}\right)=(1-a) . \mathrm{P}_{2}$.

So: under the legal regulation sub a) both subjects will be better off compared to situation A: they will share profit corresponding to surface $\mathrm{P}_{2}$.

\section{b) Legal regulation that on the contrary forbids pollution, the damaged can halt production of the contaminator.}

Without agreement on compensation the contaminator is forced to stop its production (point B). Contingent agreement of both subjects on compensation for damage caused 
by pollution amounting for $\mathrm{P}_{4}+a . \mathrm{P}_{3}$, where $0<a<1$, is beneficial for both subjects. Compared to situation $\mathrm{B}$ they gain:

- the contaminator amount $\mathrm{P}_{3}+\mathrm{P}_{4}-\left(\mathrm{P}_{4}+a \cdot \mathrm{P}_{3}\right)=(1-a) . \mathrm{P}_{3}$,

- the damaged amount $\quad a . \mathrm{P}_{3}$.

So: also under the legal regulation sub $b$ ), both subjects will be better off at the efficient level of pollution $x^{*}$ compared to situation $\mathrm{B}$, they will share profit corresponding surface $\mathrm{P}_{3}$.

Regardless of legal regulation the agreement then leads to Pareto-efficient solution $x^{*}$. Of course, legal regulation considerably influences allocation. In other words: from global viewpoint the legal regulation is irrelevant, from viewpoint of individual subjects it is more than substantial.

Coase negotiation is one of available means to internalize externalities. However, fundamental problems are connected with it: beside in reality significant cost of negotiation and of proceeding lawsuits, a problem of stowaways is concerned. They may benefit from achieved agreements, in which they are not involved (and thus not paying transaction costs), whereas excluding them from this benefit can be impossible. Other problem is frequent dominant position of the contaminator on the market of permits for exhalation, which can outbalance share on benefit from negotiation heavily in favour of the contaminator.

An alternative method of internalization of the externality is imposing Pigou tax on the contaminator in an amount equal to the marginal damage with efficient contamination:

$$
t=\Pi^{\prime}\left(x^{*}\right)=L^{\prime}\left(x^{*}\right),
$$

This taxation is designed in such a way that leads the contaminator to efficient level of contamination $x^{*}$ (see Figure 3).

Figure 3

Pigou Tax

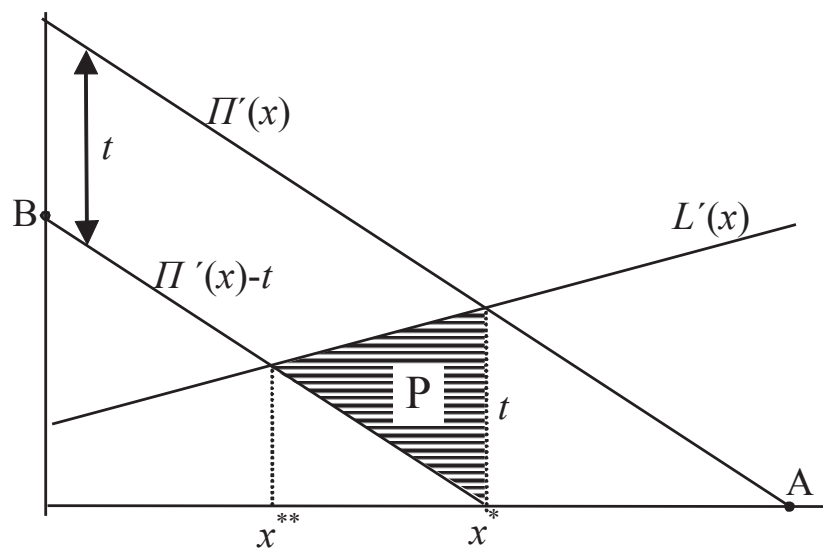

Source: Gravelle, Rees (1992) p. 521. 
Nor this method of internalisation of externalities is not without fundamental problems. First of all, there are difficulties with obtaining data necessary for calculation and setting the correct Pigou tax. Here, the contaminator is logically interested in distorting information provided to the State. Beside this problem there is another one: if the contaminator and those damaged may negotiate, this diverts the volume of contamination to level $x^{* *}$. This new situation is nevertheless Pareto inefficient in the sense, that shifting to the point $x^{*}$ would raise tax yield by $t$. $\left(x^{*}-x^{* *}\right)$. This is more than profit of both subjects from their agreement: surface $\mathrm{P}$ of hatched triangle in Figure 2 is necessarily only one part of surface of the rectangle with sides $t$ and $x^{*}-x^{* *}$.

In this sense combination of taxation and providing space for negotiation is unfavourable. The State can avoid this by using the Pigou tax for compensatory subsidy to the damaged in an amount of suffered loss $\Pi\left(x^{*}\right)$. Thereby, motivation of the damaged to negotiate on compensation disappears; this leads to an efficient level of pollution. This does not hold, if the damaged is able to attenuate damages caused by the contaminator and compensation is changing according to the amount of damage: then the amount of expenses for reducing the damage will be lower than efficient. See Chapter 18B in Gravelle, Rees (1992) or Baumol (1972).

The State should be interested, that ecological damages would be repaired and ecological investments would be financed by those subjects who can achieve remedy with lowest possible cost. To achieve this, the State admittedly has not information on necessary cost of ecological measures. In addition, an ethically questionable principle is concerned: if the damaged party (e.g. doctor) has a possibility to remove the problem in a cheaper way (e.g. acoustic shielding) than originator of the negative externality (e.g. stop working sweetshop), surprisingly it is the legal regulation allowing to annoy surroundings by noise without sanction which is more efficient (see Chapter 18 in Frank, 1995).

\section{Generalized Coase Theorem for Negative Externalities in the Economy with of Maximizing Probability of Survival}

Contrary to the standard model we will in this chapter assume more generally that both producers (the contaminator and the damaged) maximize probability of their survival. Standard model of Coase Theorem does not allow for modelling of the behaviour of the subjects that do not use only profit criterion. Criterion of the maximization of the probability of survival will allow us to do so and thus will make it possible to model wider sphere of problems from the optimization of the ecological burden.

Let us mark (index $j=1$ belongs to the contaminator, index $j=2$ to the damaged):

$x \quad$ volume of contamination,

$d_{j}(x)$ income of $j$-th subject (with inclusion of provided or obtained contingent compensation from the other subject) under activity of the contaminator producing contamination in amount $x$;

$b_{j} \quad$ border of certain extinction of $j$-th subject caused by its low income. 
We assume that $d_{l}(x)$ is increasing, because a bigger reduction of contamination is only possible at the cost of bigger reduction of income. On the contrary, $d_{2}(x)$ is decreasing, because a higher contamination affects the damaged more. Since it is possible to assume decreasing marginal impact of reducing the cost of keeping contamination below limit $x$, purely concave form of $d_{l}(x)$ can be assumed.

We will again distinguish two alternatives of legal regulation:

\section{a) The damaged may not halt production of the contaminator}

In this alternative, the damaged one must - if he wants to limit production of the contaminator - pay a compensation. Final decision is made by the contaminator. Let us mark:

$\tau \quad$ compensation paid by the damaged,

$x_{1}(\tau)$ variant offer by the damaged, i.e. the volume of the contaminator's production, at which the damaged is willing to give him compensation $\tau$,

$x_{2}(\tau)$ volume of production of the damaged with ecological burden given by the volume of the contaminator's production $x_{1}(\tau)$,

$p_{1} \quad$ price of output of the contaminator,

$p_{2} \quad$ price of output of the damaged,

$\varphi_{1}(\tau)$ income of the contaminator (including compensation provided by the damaged) depending on the volume of compensation $\tau$.

Concerning function $x_{1}(\tau)$, it is reasonable to presume that it is decreasing function, because a bigger decrease of contamination is accompanied with a higher compensation and vice versa. As according to the assumption, Pareto survival probability is the utility measure of the damaged, the volume of production and amount of compensation are connected together by the condition

$$
\frac{b_{2}}{p_{2} \cdot x_{2}(\tau)-\tau}=\frac{b_{2}}{p_{2} \cdot x_{2}^{0}},
$$

where $x_{2}^{0}=x_{2}(0)$. Hence it follows

$$
\begin{aligned}
& x_{2}(\tau)=\frac{p_{2} \cdot x_{2}^{0}+\tau}{p_{2}}=x_{2}^{0}+\frac{\tau}{p_{2}} . \\
& \phi_{1}(\tau)=p_{1} \cdot x_{1}(\tau)+\tau=p_{1} \cdot x_{1}(\tau)+p_{2} \cdot\left(x_{2}(\tau)-x_{2}^{0}\right)
\end{aligned}
$$

Probability of survival of the contaminator in case he is not restricted by law, disregards his influence upon the damaged and no compensation is offered to him $(\tau=0)$ could be set as

$$
p_{1}(0)=1-\frac{b_{1}}{\phi_{1}(0)}=1-\frac{b_{1}}{p_{1} \cdot x_{1}^{0}},
$$


where $x_{1}^{0}=x_{1}(0)$. Probability of survival of the contaminator in case he accepts subsidy $\tau>0$ is

$$
p_{1}(\tau)=1-\frac{b_{1}}{\phi_{1}(\tau)},
$$

where the denominator is given by equation $(*)$.

The optimal (from viewpoint of the contaminator) amount of compensation $\tau^{*}>0$ must fulfil the condition $p_{1}(\tau)=0$, thus

$$
\begin{aligned}
& \frac{b_{1} \cdot \phi_{1}^{\prime}\left(\tau^{*}\right)}{\left[\phi_{1}\left(\tau^{*}\right)\right]^{2}}=0 \\
& \phi_{1}^{\prime}\left(\tau^{*}\right)=0
\end{aligned}
$$

We will substitute from the equation $(*)$ :

$$
\phi_{1}^{\prime}\left(\tau^{*}\right)=p_{1} \cdot x_{1}^{\prime}\left(\tau^{*}\right)+p_{2} \cdot x_{2}^{\prime}\left(\tau^{*}\right)=0
$$

So: if this equation $(*)$ has solution $\tau^{*}>0$, then in this optimum the maximal total volume of production of both subjects is

$$
U(\tau)=p_{1} \cdot x_{1}(\tau)+p_{2} \cdot x_{2}(\tau)
$$

We can treat this function as global ("social") criterion, because it is sum of sales revenues (except constant $b_{1}-b_{2}$ ) multiplied by survival probability for the relevant subject:

$$
\left(1-\frac{b_{1}}{p_{1} \cdot x_{1}(\tau)}\right) \cdot p_{1} \cdot x_{1}(\tau)+\left(1-\frac{b_{2}}{p_{2} \cdot x_{2}(\tau)}\right) \cdot p_{2} \cdot x_{2}(\tau)=p_{1} \cdot x_{1}(\tau)+p_{2} \cdot x_{2}(\tau)-b_{1}-b_{2}
$$

So: in the alternative a, where it is the contaminator who decides about the amount of compensation on the basis of a helpful offer by the damaged, this negotiation establishes the global ("social") optimum.

Concerning ecological investment with cost of I and with given ecological effect which is socially (e.g. via voting in referendum) regarded as worth implementing, this is under alternative a) of course financed by the damaged; for him it brings increase in probability of extinction from $\frac{b_{2}}{p_{2} \cdot x_{2}(\tau)}$ to $\frac{b_{2}}{p_{2} \cdot x_{2}(\tau)-I}$.

\section{b) The damaged may stop production of the contaminator}

In this alternative, the contaminator (subject with index $j=1$ ) must pay to the damaged (subject with index $\mathrm{j}=2$ ) compensation for his damage. Final decision is made by the damaged; the contaminator presents a variant offer. So it is the damaged who decides - on the basis of a helpful offer of the contaminator - on amount of compensation and consequently on the volume of contamination. 
We shall mark:

$\tau \quad$ compensation paid by the contaminator;

$x_{1}(\tau)$ variant offer by the contaminator, i.e. the required permission of the volume of his production for compensation $\tau$;

$x_{2}(\tau)$ volume of production of the damaged under ecological burden given by the volume of production of the contaminator $x_{1}(\tau)$;

$p_{1} \quad$ price of output of the contaminator;

$p_{2} \quad$ price of output of the damaged;

$\varphi_{i}(\tau)$ income of the i-th subject (with inclusion of compensation paid to the damaged) depending on the amount of compensation $\tau$.

Concerning variant offer $x_{1}(\tau)$, we assume it is increasing function, because higher compensation means higher allowed contamination. Maximizing probability of his own survival leads the contaminator to the condition:

$$
\frac{b_{1}}{p_{1} \cdot x_{1}(\tau)-\tau}=\frac{b_{1}}{p_{1} \cdot x_{1}^{0}}
$$

where $x_{1}^{0}=x_{1}(0)$. Here from for the offer of the contaminator implies

$$
\begin{aligned}
& x_{1}(\tau)=\frac{p_{1} \cdot x_{1}^{0}+\tau}{p_{1}}=x_{1}^{0}+\frac{\tau}{p_{1}}, \\
& \phi_{2}(\tau)=p_{2} \cdot x_{2}(\tau)+\tau=p_{2} \cdot x_{2}(\tau)+p_{1} \cdot\left(x_{1}(\tau)-x_{1}^{0}\right)
\end{aligned}
$$

Probability of survival of the damaged - if he does not accept any compensation $(\tau=0)$ - is

$$
p_{2}(0)=1-\frac{b_{2}}{\phi_{2}(0)}=1-\frac{b_{2}}{p_{2} \cdot x_{2}^{0}},
$$

where $x_{2}^{0}=x_{2}(0)$. Probability of survival of the damaged - if he accepts subsidy $\tau>$ 0 - is

$$
p_{2}(\tau)=1-\frac{b_{2}}{\phi_{2}(\tau)}
$$

where the denominator is given by the equation $(* *)$. Optimal (from the point of vie, of the contaminator) amount of compensation $\tau^{*}>0$ must fulfil the condition $p_{2}(\tau)=0$. After substitution similarly like in alternative A we get

$$
\phi_{2}^{\prime}\left(\tau^{*}\right)=0 \text {. }
$$

We substitute from the equation $(* *)$ :

$$
\phi_{2}^{\prime}\left(\tau^{*}\right)=\phi_{2}^{\prime}\left(\tau^{*}\right)=p_{1} \cdot x_{1}^{\prime}\left(\tau^{*}\right)+p_{2} \cdot x_{2}^{\prime}\left(\tau^{*}\right)=0 .
$$

If an optimum exists (i.e. equation $(* *)$ has the solution $\tau^{*}>0$ ), then the value of the "social" criterion $U(\tau)$ is here at its maximum - same as in alternative A. 
It holds for both alternatives A and B that optimum of the decision maker is identical with the global ("social") optimum.

It is of course different if an ecological investment is concerned. While in standard Coase Theorem it holds, that it is "from the social point of view" the same which legal regulation is valid (and who thus will finance the investment), in generalized microeconomics it is not all the same.

Value of the "social" criterion after implementation of the investment I in alternative $\mathrm{A}$ is

$$
U^{(A)}(\tau)=\left(1-\frac{b_{1}}{p_{1} \cdot x_{1}\left(\tau^{*}\right)}\right) \cdot p_{1} \cdot x_{1}(\tau)+\left(1-\frac{b_{2}}{p_{2} \cdot x_{2}(\tau)-I}\right) \cdot p_{2} \cdot x_{2}(\tau),
$$

whereas value of the criterion after implementation of the investment I in alternative $\mathrm{B}$ is

$$
U^{(B)}(\tau)=\left(1-\frac{b_{1}}{p_{1} \cdot x_{1}\left(\tau^{*}\right)-I}\right) \cdot p_{1} \cdot x_{1}(\tau)+\left(1-\frac{b_{2}}{p_{2} \cdot x_{2}(\tau)}\right) \cdot p_{2} \cdot x_{2}(\tau),
$$

whereas [just except an absolutely unrealistic case $b_{1}=b_{2} \& p_{1} \cdot x_{I}\left(\tau^{*}\right)=p_{2} \cdot x_{2}\left(\tau^{*}\right)$ ] it certainly holds

$$
U^{(A)}(\tau) \neq U^{(B)}(\tau) .
$$

On the basis of achieved conclusions we now will enunciate the following theorem:

\section{Generalized Coase Theorem for negative externalities:}

Let us suppose, that

- property rights are well defined,

- agents maximize their own Pareto survival probability,

- transaction costs are zero.

Then:

- negotiation about compensation for ecological damage will bring optimization of benefit of both subjects and social benefit irrespective the legal regulation, but:

- legal regulation seen will influence individual and social "costs" (measured by considered criteria both of individuals and society) of investments on rectification of ecological damages. If the legal regulation is detrimental for the more endangered subject, these "costs" are superior than in the opposite case.

As far as the first assertion is concerned, at point the generalized microeconomics - compared to Coase Theorem in standard microeconomics - does not differ from paradigm homo oeconomicus. But (in contradiction to Coase Theorem in standard microeconomics): legal regulation and initial distribution of agents' wealth influence ecological investments. 


\section{Coase Theorem for Positive Externalities}

The basic principle of Coase Theorem holds symmetrically also for positive externalities. In the case an unregulated market the positive externality related activity is offered in lesser extent than it would be socially optimal. The solution of the positive externality problem under standard Coase framework would be thus Pigouian subsidy ("negative tax") to the producer of the positive externality (see Varian, 1992). If the production their provider, which he will select when maximizing his own income, is from the point of view of recipient of externality seen as low, he can stimulate the provider financially. Positive externalities are activities including external costs to their producer that bring benefit to the subjects not participating on these activities. Similarly to the negative externalities they again lead to disturbance of the competitive ideal: relevant product seems to be more expensive than it is from the point of view of the whole society. Produces amount of this good $\mathrm{Y}$ is in private optimum EP lower than it is socially optimal (point $\mathrm{E}_{\mathrm{S}}$ ). Social costs of this inefficiency are marked by the shaded area in Figure 4, where $\mathrm{MU}_{\mathrm{S}}$ and $\mathrm{MU}_{\mathrm{P}}$ depict social and private utility, $\mathrm{S}$ depicts supply (marginal costs).

Figure 4

Social Costs of Inefficiency Arising from the Positive Externality

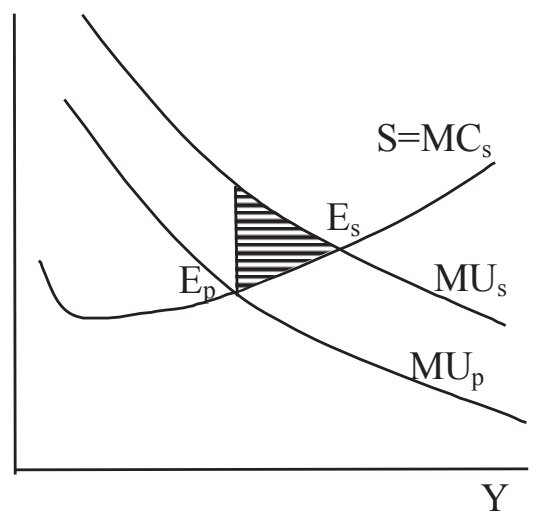

Application of Coase Theorem on positive externalities has certain specificities: a compensation for damage caused by another subject is not concerned, but it is a redistributing action: one subject supports the other, about whose survival and possibly increasing his activity the first subject has his own economic interest. Negotiation for subsidy (negative compensation) between subjects producing and utilizing positive externalities brings (under the assumption of negligible cost of negotiation) an efficient result. Thus: Coase Theorem for positive externalities says that maximization of private benefits leads to Pareto-optimal allocation of resources and, at the same time, to globally "socially" optimal result. 
Figure 5

Efficient Level of Positive Externality

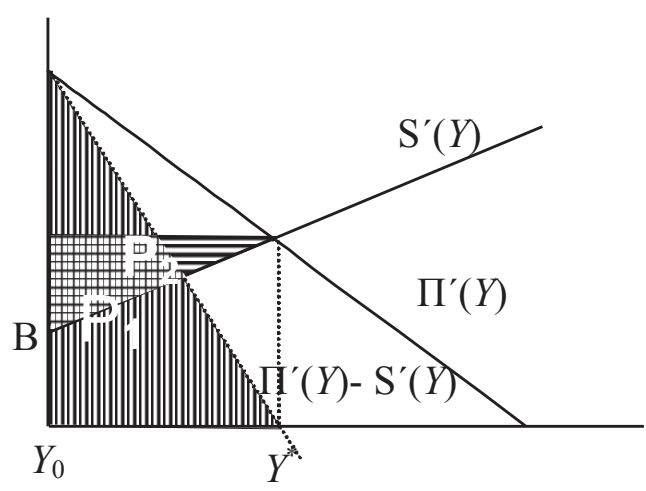

Figure 5 illustrates increasing marginal profit of the subject $\Pi^{\prime}(Y)$ without counting the subsidy to the producer of the positive externality. $\mathrm{S}(Y)$ is the size of the subsidy that would persuade him to the production in volume $Y$. $\mathrm{S}^{\prime}(Y)$ is the marginal value of this subsidy thus the increase of the subsidy that would persuade producer to increase his output by one unit. Due to the decreasing marginal returns from scale the increasing of the production more and more expensive and thus the $\mathrm{S}^{\prime}(Y)$ is the increasing function and $\Pi^{\prime}(Y)$ decreasing function.

If there is no subsidy to the producer of the positive externality, he produces $Y_{0}$ (point B). The recipient of the positive externality increases his subsidy until the increase of the profit for (small) unit equals this increase of subsidy, thus until production $Y^{*}$.

Compared to the point $\mathrm{B}$ the producer of the positive externality receives the profit corresponding to the area $\mathrm{P}_{2}$, the provider of subsidy receives the profit corresponding to the area $\mathrm{P}_{1}$. Similarly to the negative externalities the optimal level $Y^{*}$ does not depend whether or not is the recipient of the positive externality forced by legal regulation to compensate the producer of the positive externality.

\section{Generalized Coase Theorem for Positive Externalities and Subjects Maximizing Probability of Their Own Survival}

As an example, we will use relation of a fruit-grower and a beekeeper. There are two possibilities: we either assume that the number of bee colonies is not sufficient for pollination of the trees of the fruit-grower; he is then willing to subsidize - in his own interest - the beekeeper. Or, on the contrary, number of trees will not be sufficient to assure pollen for bee colonies; then beekeeper will provide - also in his own interest certain financial means for enlargement plantation of fruit trees.

Let us supposed, for example, that the bees are "the bottleneck", so that is the fruit-grower who receives the positive externality. In purely model look the opposite case - would just mean renumbering of the subjects.

Let us supposed further, that survival of both subjects, i.e. of the provider and of the recipient of positive externality, depends entirely on their income.

Earnings of the recipient of the positive externality (the fruit-grower) constitute 
exclusively sales of fruit in quantity $q_{s}$ with price $\pi_{s}$, so the earnings of the fruitgrower is $e_{s}=q_{s} . \pi_{s}$. Let us assume in a simplified way, that if the provider of positive externality (the beekeeper), will become extinct, then $q_{s}=0$. Income of the fruitgrower, who provides contribution $\sigma$ to the beekeeper, is $d_{s}=e_{s}-\sigma$.

Income $d_{v}$ of the provider of the positive externality (beekeeper) presents in part sale of honey in quantity $q_{v}$ with unit price $\pi_{v}$, in part contribution from the fruit-grower $\sigma$, so $d_{v}=e_{v}+\sigma$ where $e_{v}=q_{v} . \pi_{v}$.

Let us suppose that in both cases concerned this is the only source of subject's income and that low income is his only risk, given by Pareto first degree distribution. Let us mark bs subsistence level (boundary of cessation zone) for fruit-grower (recipient of the positive externality) and by the boundary of cessation zone for the beekeeper (provider of positive externality).

\section{A. Model of an only provider of positive externality}

Let us suppose that production of the fruit-grower $q_{s}$ is smooth and increasing function of the production of honey $q_{v}$ :

$$
q_{s}=q_{s}\left(q_{v}\right) .
$$

Price of fruit $\pi_{s}$ (as well as price of honey $\pi_{v}$ ) is given, consequently also function of earnings of the fruit-grower is smooth and increasing function:

$$
e_{s}\left(q_{v}\right)=\pi_{s} \cdot q_{s}\left(q_{v}\right)
$$

Let us suppose further, that production of the beekeeper $q_{v}$ is also given and that there is a threat (based on insufficient income) that the beekeeper will become extinct and his production falls to zero. His income after obtaining subsidy $\sigma$ is

$$
d_{v}=e_{v}+\sigma=q_{v} \cdot \pi_{v}+\sigma
$$

and his probability of survival is

$$
p_{v}(\sigma)=\frac{d_{v}-b_{v}}{d_{v}}=1-\frac{b_{v}}{q_{v} \cdot \pi_{v}+\sigma} .
$$

On the other hand, the fruit-grower is exposed to two threats: partly by his low own income, partly by extinction of the beekeeper. Income of the fruit-grower for his own consumption (after deduction of the contribution to the beekeeper) is

$$
d_{s}=\pi_{s} \cdot e_{s}\left(q_{v}\right)-\sigma
$$

with survival probability given by product of survival probability of the beekeeper and of avoiding the risk of extinction based on a low personal income:

$$
p_{s}(\sigma)=\left[1-\frac{b_{v}}{q_{v} \cdot \pi_{v}+\sigma}\right] \cdot\left[1-\frac{b_{s}}{\pi_{s} \cdot q_{s}\left(q_{v}\right)-\sigma}\right]
$$

Let us mark $\mathrm{C}_{1}$ the first multiplicand and $\mathrm{C}_{0}$ the second one:

$$
p_{s}(\sigma)=C_{1}(\sigma) \cdot C_{0}(\sigma) \text {. }
$$


Condition for maximum is

$$
\begin{aligned}
& C_{1}^{\prime}(\sigma) \cdot C_{0}(\sigma)+C_{0}^{\prime}(\sigma) \cdot C_{1}(\sigma)=0, \\
& \frac{C_{1}^{\prime}(\sigma)}{C_{1}(\sigma)}=-\frac{C_{0}^{\prime}(\sigma)}{C_{0}(\sigma)}, \\
& {\left[\ln C_{1}(\sigma)\right]^{\prime}=-\left[\ln C_{0}(\sigma)\right]^{\prime} .}
\end{aligned}
$$

As differentiated functions on both sides of the equation are (under accepted assumption of smoothness of the function $q_{s}\left(q_{v}\right)$ ) uniquely invertible functions, purely monotonous, smooth and positive, and because

$$
\begin{aligned}
& {\left[\ln C_{1}(0)\right]^{\prime}<-\left[\ln C_{0}(0)\right]^{\prime} \quad \text { and at the same time }} \\
& \lim _{\sigma \rightarrow \infty}\left[\ln C_{1}(\sigma)\right]^{\prime}>-\lim _{\sigma \rightarrow \infty}\left[\ln C_{0}(\sigma)\right]^{\prime}
\end{aligned}
$$

there has been an only optimal level of subsidy $\sigma^{*}$. It is obvious, that for the subsidy it holds that $\sigma^{*}>0$, so it holds independently on parameters of the model, that if there is an only beekeeper in the location, it is economically advantageous for fruit-growers to subsidize him.

\section{B. Model with more providers of positive externality}

First we will analyze situation with two beekeepers: will the fruit-grower pick one or will he support both? Will he prefer the stronger one (providing him - compared with the weaker one - higher degree of certainty) or the weaker one (existence of two beekeepers can suit the fruit-grower more)? Will the fact, that there are two beekeepers, influence the amount of subsidy? We will show that our approach will enable to analyze such non-trivial problems.

We suppose, that the fruit-grower perishes, only when both beekeepers perish. Probability of his survival is then given by the relation:

$$
p_{s}\left(\sigma_{1}, \sigma_{2}\right)=\left[1-\frac{b_{s}}{\pi_{s} \cdot q_{s}\left(q_{v}\right)-\sigma}\right] \cdot\left[1-\frac{b_{v}{ }^{1}}{q_{v}{ }^{1} \cdot \pi_{v}+\sigma_{1}}\right] \cdot\left[1-\frac{b_{v}{ }^{2}}{q_{v}{ }^{2} \cdot \pi_{v}+\sigma-\sigma_{1}}\right]
$$

whereas production of honey is given by the sum of the production of both beekeepers:

$$
q_{v}=q_{v}{ }^{1}+q_{v}^{2}
$$

Firstly let us suppose that both beekeepers are in the same economic position, i.e. $b_{v}{ }^{1}=b_{v}{ }^{2}, q_{v}{ }^{1}=q_{v}{ }^{2}=q_{v} / 2$ and so they are threatened by extinction in the same way. In this case the fruit-grower has of course no reason to prefer one beekeeper to the other (they are identical from his look), therefore we can assume $\sigma_{1}=\sigma_{2}=\sigma / 2$. Probability of the fruit-grower's survival is then 


$$
p_{s}\left(\frac{\sigma}{2}, \frac{\sigma}{2}\right)=\left[1-\frac{b_{s}}{\pi_{s} \cdot q_{s}\left(e_{v}\right)-\sigma}\right] \cdot\left[1-\frac{2 b_{v}}{q_{v} \cdot \pi_{v}+\sigma}\right]^{2} .
$$

If the beekeepers are in unequal economic position, the fruit-grower will prefer the weaker one. If even after obtaining the whole subsidy $\sigma$ probability of extinction of the weaker one remains bigger, he will get all. If not, the subsidy will be divided in the following way:

$$
\begin{gathered}
\sigma_{1}=\sigma_{0}+\frac{\sigma-\sigma_{0}}{2} . \\
\sigma_{2}=\frac{\sigma-\sigma_{0}}{2} .
\end{gathered}
$$

where $\sigma_{0}$ is subsidy, equalizing rate of risk of extinction of both bee-keepers, i.e.

$$
1-\frac{b_{v}{ }^{1}}{d_{v}{ }^{1}+\sigma_{0}}=1-\frac{b_{v}^{2}}{d_{v}{ }^{2}} .
$$

For $n$ beekeepers with identical economic position the subsidy will be divided evenly, i. e. $\sigma_{j}=\sigma / n$, and for survival probability of the fruit-grower will hold similarly as in the case where $n=2$

$$
p_{s}\left(\frac{\sigma}{n}, \ldots, \frac{\sigma}{n}\right)=\left[1-\frac{b_{s}}{\pi_{s} \cdot q_{s}\left(e_{v}\right)-\sigma}\right] \cdot\left[1-\frac{n \cdot b_{v}}{q_{v} \cdot \pi_{v}+\sigma}\right]^{n} .
$$

By providing globally identical subsidy $\sigma$ to more beekeepers, the fruit-grower will heighten probability of his survival, whereas the higher is number of beekeepers $\mathrm{n}$, the higher is this increase of probability of his own survival. It was proven by numerical experiments, which we undertook for case of equal economic position of all beekeepers and for tenfold earnings of the fruit-grower compared to aggregate earnings of beekeepers. Results of these experiments are recorded in Figure 6.

Figure 6

Increase of Probability of Personal Survival of the Fruit-Grower in \% (vertical axis) as Consequence of his Contribution to Beekeepers in \% of His Own Income (horizontal axis)

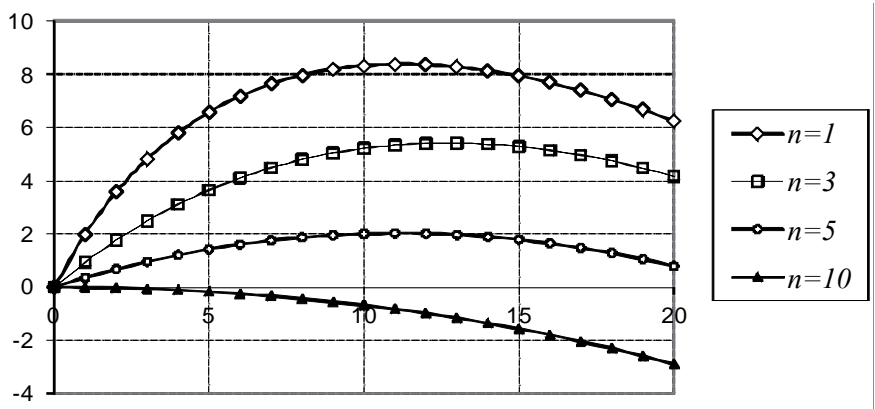


Effect of subsidy (in optimum roughly $10 \%$ of the fruit-grower's income) is thus relatively highest in case of an only beekeeper. This conclusion is logical: the lower is the number of beekeepers, the higher is the risk to fruit-grower extinction due to extinction of all beekeepers and thereby ceteris paribus also higher motivation to provide a subsidy. Under higher number of beekeepers, the fruit-grower (seeing that by providing subsidy he threatens himself by decreasing his income) will decrease the subsidy. Very high (double-digit) number of providers of positive externality will cause, that the fruit-grower will withdraw from subsidizing.

These conclusions are of course conditioned by restrictive and simplifying assumptions of the model. It is indeed valid for every microeconomic model.

\section{Conclusion}

The generalisation of the Coase Theorem for negative externalities and for subjects maximising their probability of economic survival has shown that, similarly to the standard Coase Theorem, for both subjects (contaminator and harmed) possibility of negotiation improves their position. However, contrary to the standard model, the volume of investment in remedy of ecological harm is not independent of legal regulation. Moreover, results depend on the relation of volume of wealth of involved subjects. This conclusion corresponds with outcomes by Allan Randall (see Randall, 1974) who concludes that income distribution of both parties influences agreement on compensation and thus also optimal production.

We also studied problem of the positive externality. Our generalized microeconomics enabled us to model how optimal level of subsidy depends on the number of providers of positive externality.

\section{References:}

Baumol, W. J. (1972), "On Taxation and the Control of Externalities." American Economic Review, 62(3), pp. 307-322.

Bernholz, P. (1999), "The Generalized Coase Theorem and Separable Individual Preferences: An Extension." European Journal of Political Economy. June 1999, Volume 15, Issue 2, pp. 331-335.

Coase, R. H. (1960), "Problem of Public Costs." Journal of Law and Economics. 1960, No. 3, pp. 144-171.

Cooper, R. N. (1995), "The Coase Theorem and International Economic Relations." Japan and the World Economy. May 1995, Volume 7, Issue 1, pp. 29-44.

Frank, R. H. (1994), Microeconomics and Behavior. McGraw-Hill, Inc.

Gravelle, H., Rees, R. (1992), Microeconomics. North Holland, London: Longman Group UK Limited, 1992.

Hlaváček, J., Hlaváček, M. (2011), (Generalized Microeconomics). Praha: Karolinum, 2011. ISBN: 978-80-246-2024-4

Hoffman, E., Spitzer, M. L. (1982), "The Coase Theorem: Some Experimental Tests." Journal of Law and Economics. April 1982, Vol. 25, No. 1, pp. 73-98.

Kahneman, D., Knetsch, J. L., Thaler, R. H. (1990), "Experimental Test of the Endowment Effect and the Coase Theorem." Journal of Political Economy, 98(6), pp. 1325-1348. 
Lin, Steven, A. Y., ed. (1976), Theory and Measurement of Economic Externalities. New York: Academic Press, Inc.

Martens, B. (1996), "Towards a Generalized Coase Theorem." Paper presented at a conference on Commerce, complexity and evolution at the University of New South Wales, Sydney (12-13th February 1996).

Medema, S., Samuels, W. (1996), "Ronald Coase and Coasean Economics: Some Questions, Conjectures and Implications," in Samuels, W. et.al., The Economy As a Process of Valuation. Cheltenham: Edward Elgar, 1996.

Persson, T. (1997), "Prize Lectures in Economic Sciences 1991-1995." Stockholm University, July 1997.

Randall, A. (1974), "Coasian Externality Theory in a Policy Context." Natural Resources Journal, January 1974, 14, pp. 35-54.

Reichlová, N., Cahlík, T., Hlaváček, J., Švarc, P., Chytilová, J. (2006), "Multiagent Approaches in Economics," in Lukáš, L. (ed.), Mathematical Methods in Economics 2006. Pilsen: University of West Bohemia, 2006, pp. 77-98. ISBN 80-7043-480-5.

Varian, H. R. (1992), Microeconomic Analysis. 2nd ed. New York: W. W. Norton and Company.

Shogren, J. F. (1992), "An Experiment on Coasian Bargaining over ex ante Lotteries and ex post Rewards." Journal of Economic Behavior \& Organization, January 1992, Vol. 17, No. 1, pp. 153-169.

Zivin, J. G., Small, A. A. (2003), "Risk Sharing in Coasean Contracts." Journal of Environmental Economics and Management, Elsevier, Vol. 45(2, Supple), pp. 394-415. 